\title{
Mark DOYLE, Fighting like the Devil for the Sake of God. Protestants, Catholics and the Origins of Violence in Victorian Belfast
}

Manchester-New York, Manchester University Press, 2009, 296 p.

\section{Véronique Altglas}

\section{QpenEdition}

\section{Journals}

Édition électronique

URL : http://journals.openedition.org/assr/22604

DOI : $10.4000 /$ assr.22604

ISSN : $1777-5825$

Éditeur

Éditions de l'EHESS

Édition imprimée

Date de publication : 31 décembre 2010

Pagination : 9-242

ISBN : 9782713223013

ISSN : 0335-5985

\section{Référence électronique}

Véronique Altglas, « Mark doyLE, Fighting like the Devil for the Sake of God. Protestants, Catholics and the Origins of Violence in Victorian Belfast », Archives de sciences sociales des religions [En ligne], 152 I octobre-décembre 2010, document 152-43, mis en ligne le 12 mai 2011, consulté le 21 septembre 2020. URL : http://journals.openedition.org/assr/22604 ; DOI : https://doi.org/10.4000/assr.22604

Ce document a été généré automatiquement le 21 septembre 2020.

(C) Archives de sciences sociales des religions 


\title{
Mark DOYLE, Fighting like the Devil for the Sake of God. Protestants, Catholics and the Origins of Violence in Victorian Belfast
}

Manchester-New York, Manchester University Press, 2009, 296 p.

\author{
Véronique Altglas
}

\section{RÉFÉRENCE}

Mark DoYLE, Fighting like the Devil for the Sake of God. Protestants, Catholics and the Origins of Violence in Victorian Belfast, Manchester-New York, Manchester University Press, 2009, 296 p.

1 Pourquoi et comment la violence devient-elle un moyen par lequel les individus expriment des identités religieuses différentes? C'est la question que cette étude historique se propose de traiter, en analysant une «tradition de la violence» entre catholiques et protestants qui émerge entre 1850 et 1865 à Belfast. Si les catholiques et protestants irlandais se sont opposés violemment depuis le XVII e siècle, au cours de la seconde moitié du XIX ${ }^{e}$ siècle cette violence prend de nouvelles formes, s'inscrit dans la mémoire collective des deux communautés et marque la vie urbaine de telle sorte qu'au fil du temps elle pourra paraître récurrente et banale. C'est autour de 1850 que Belfast connaît ses premiers succès industriels ainsi qu'une urbanisation extrêmement rapide, liée autant au processus d'industrialisation qu'aux migrations causées par la Grande Famine irlandaise des années 1840. La moitié du XIX ${ }^{e}$ siècle est donc une époque au cours de laquelle les milieux populaires catholiques et protestants tentent de s'ajuster à ces changements sociaux importants et se façonnent de nouvelles identités dans une ville en pleine transformation. La violence entre catholiques et protestants, qui existait en milieu rural, se trouve alors transposée dans les quartiers ouvriers de Belfast, sous 
une forme urbaine, moins prévisible, et dont la durée et la magnitude seront sans précédent. L'auteur reconnaît que de nombreuses études ont déjà cherché à identifier les causes de la violence en Irlande du Nord, toutefois il considère que peu d'entre elles se sont attachées à comprendre pourquoi la violence y est devenue banale, pourquoi certains acteurs sociaux ont pu choisir la violence pour exprimer leur hostilité, et quel rôle elle a joué dans la polarisation des deux communautés. En d'autres termes, ce qui semble manquer à l'analyse de la situation nord-irlandaise est une compréhension de la manière dont la violence opère dans une société donnée, comment celle-ci en vient à épouser les contours de la vie quotidienne et à structurer les relations sociales. C'est pourquoi il semble que ce livre pourra intéresser ceux qui, de manière générale, réfléchissent sur les liens entre religion et violence, violence et espace, ou encore violence et réseaux sociaux.

2 En effet, Mark Doyle insiste tout d'abord sur l'importance de réseaux sociaux complexes afin de comprendre véritablement l'explosion des émeutes opposant catholiques et protestants dans le Belfast de l'ère victorienne. Organisations fraternelles ou secrètes, institutions religieuses, alliances politiques, mais aussi relations entre élites et classes ouvrières, entre modérés et «combattants», entre hommes et femmes, entre générations; tous ces liens jouent un rôle fondamental quand ils sont activés dans les moments de conflit, permettant une expansion de la violence tout à fait singulière. Ainsi, le premier chapitre du livre montre comment des réseaux politiques et évangéliques, influents et bien organisés, se sont appuyés sur un certain anticatholicisme pour unir classes moyennes et ouvrières protestantes, et donner une identité protestante à la ville. Si les réseaux sociaux protestants ont pu instrumentaliser le sectarisme, en revanche, les organisations communautaires catholiques ont échoué à l'endiguer. Le deuxième chapitre insiste sur le manque de pouvoir et de ressources de la minorité catholique, vivant au sein d'une population largement dominante et hostile. Ce contexte a nourri un sentiment de vulnérabilité et une tendance, pour les classes moyennes catholiques, à faire profil bas, laissant aux catholiques les plus défavorisés le soin de trouver des moyens de se défendre et de s'affirmer. C'est en raison de la profonde démoralisation de ces derniers que leur peur a pu être instrumentalisée par une minorité. Car, de manière générale, c'est une minorité, tant du côté protestant que catholique, qui fut impliquée dans les actes violents et qui a su imposer son hégémonie sur leur communauté respective, via intimidations, chantages, et surtout expulsions des «outsiders» de manière à créer des lieux de travail et de résidence «purs», c'est-à-dire totalement ségrégués.

En outre, ce livre resitue ces violences dans le contexte plus large des relations d'une population à l'État qui la gouverne. L'État britannique a été incapable de contenir la violence à Belfast, non par manque de moyen, mais parce qu'il n'a pas su assurer sa légitimité auprès de l'une ou l'autre communauté. Les sentiments antiétatiques des catholiques avaient pour origine, d'une part, la manière dont les représentent politiques locaux ont exploité l'anticatholicisme protestant pour les exclure du pouvoir politique, et, d'autre part, les relations hostiles qu'ils entretenaient avec le bras armé de ce gouvernement conservateur local, la police (chap.4). La méfiance vis-à-vis de l'État avait pour les protestants une tout autre origine: alors que l'élite locale tentait de conserver la main sur les affaires de la ville, les gouvernements britanniques successifs cherchaient à créer un pouvoir central et impartial basé à Dublin, loin donc du bastion protestant de l'Ulster (chap.5). Ce manque de confiance envers un État qui n'a pas su 
imposer sa légitimité ou son usage de la force comme seule violence légitime a contribué à la formation de "groupes de vigilance» armés qui, au sein des deux communautés, deviennent alors des acteurs cruciaux dans l'escalade de la violence à Belfast. Il va de soi, par ailleurs, que ces tensions avec l'État font de la gestion de ces émeutes un problème proprement politique - la réponse violente de celui-ci a parfois été centrale aux conflits. Plus largement, l'auteur fait de l'impérialisme un facteur important de compréhension de la violence à Belfast en ce qu'il explique l'intensité du sectarisme de la ville par l'anxiété des deux communautés quant à leur place respective au sein de l'Empire britannique. À ce titre, la comparaison de Belfast avec Glasgow est intéressante, car c'est une ville qui a également connu des tensions sectaires mais à un bien moindre degré (chap.7). Contrairement aux protestants de l'Ulster, ceux de Glasgow n'ont pas connu le sentiment de représenter un fragile bastion protestant dans une Irlande largement catholique que les Britanniques pouvaient un jour quitter. Les catholiques de Glasgow, bien que minoritaires, n'ont pas été marginalisés comme l'ont été ceux d'Irlande du Nord, ni ne se seront engagés un peu plus tard dans une lutte d'indépendance nationale. Enfin, en ce qui concerne Glasgow, l'État lui-même n'était pas divisé entre une élite locale et un État central utilisant des structures de domination et des moyens coercitifs comme en Irlande, alors colonie de l'Empire britannique.

4 Enfin, en prêtant attention aux cibles attaquées, aux protagonistes impliqués, au rôle de la topographie de la ville et aux actions de la police, l'auteur s'attache à analyser comment la violence est vécue par les acteurs sociaux eux-mêmes et participe de la polarisation de la population. À partir des émeutes de 1864, les chapitres 6 et 8 , notamment, analysent la manière dont émergent des conflits beaucoup plus étendus et destructeurs qu'auparavant, attribuant de nouvelles significations aux rues, bâtiments et monuments de Belfast. Ces émeutes ont ainsi produit une mémoire collective de la violence intimement liée à la ville elle-même et ont contribué au développement d'identités spécifiques. Commémorées, représentées sous forme de gravures, contées dans des chansons populaires, ces émeutes façonneront les conflits futurs, dont la banale répétition semble pouvoir légitimer l'expression de "tradition de violence» utilisée par l'auteur. Cette analyse de la formation d'une «tradition de la violence» est particulièrement intéressante car bien des caractéristiques de celle-ci rappelleront au lecteur le déroulement particulier des «Troubles» qui ont déchiré l'Irlande du Nord un siècle plus tard. Elles permettent également de comprendre la ségrégation si singulière qui, encore aujourd'hui, divise la ville de Belfast. Plus largement, le caractère analytique et sociologique de cette étude lui confère un intérêt plus général en ce que celle-ci pourra susciter chez le lecteur une réflexion comparative sur les conditions sociales de production (et de reproduction) de la violence. 